\title{
The Outcomes of Integrating High Fidelity Simulation in Nursing Education: An Integrative Review
}

\author{
Ahmad Ayed1, Inaam Khalaf ${ }^{2}$ \\ ${ }^{1}$ School of Nursing, Arab American University, Jenin, Palestine \\ ${ }^{2}$ School of Nursing, The University of Jordan, Amman, Jordan \\ Email: Ahmad.juma@aauj.edu,khalaf12@yahoo.com
}

How to cite this paper: Ayed, A. and Khalaf, I. (2018) The Outcomes of Integrating High Fidelity Simulation in Nursing Education: An Integrative Review. Open Journal of Nursing, 8, 292-302. https://doi.org/10.4236/ojn.2018.85025

Received: April 19, 2018

Accepted: May 14, 2018

Published: May 17, 2018

Copyright (c) 2018 by authors and Scientific Research Publishing Inc. This work is licensed under the Creative Commons Attribution International License (CC BY 4.0).

http://creativecommons.org/licenses/by/4.0/

\section{(c) (i) Open Access}

\begin{abstract}
Purpose: The purpose of this review was to identify the best evidence on the effectiveness of using high fidelity simulation technology for learning outcomes in nursing education. Methods: An integrative review was used to assess the effectiveness of high fidelity simulation in nursing education. Data search was between 2008 to 2018 using Google Scholar, Scopus, Web of Science, Science Direct, Pub Med, Medline, CINAHL, EBSCO, Cochrane, ERIC, Joanna Briggs Institute and EBSCO host. A total of 17 articles met the eligibility criteria. Results: The seventeen reviewed articles were adopted mixed method designs, randomized controlled trial, quazi-experimental, and correlational studies. Themes were: self-satisfaction and confidence, clinical decision-making, and clinical judgment. Conclusion: Nursing literature supports the importance of including high fidelity simulation in nursing education. HFS provides diverse learning experiences, promotes decision-making and clinical judgment, self-satisfaction and self-confidence to develop assessment and safe practice. Implication: Nursing educators can create a variety of patient conditions for collaborative nursing care for increasing learning outcomes.
\end{abstract}

\section{Keywords}

High Fidelity Simulation, Nursing Education, Students

\section{Introduction}

Today's clinical nursing environment is more complex than ever before. As a rapidly advancing profession, nursing demands higher cognitive skills from nurses. Critical creative thinking and clinical judgment are viewed as essential 
skills for every health professional [1]. The literature indicates that most newly qualified nurses do not meet the expectations for entry level of clinical judgment

[2]. The improving critical thinking skills may become more vital than the capacity to perform related psychomotor abilities [3]. Therefore, complex clinical situations encompassing simulation using high fidelity simulation (HFS) may enhance students' ability to accomplish patients' needs in clinical practice [4]. Simulation offers a safe environment in which learners can train and make errors in a controlled environment [5] [6] [7].

There is a positive trend in learning outcomes when simulation is utilized in nursing clinical courses [8] [9] [10] [11]. Debriefing, a component of simulation learning, is the reflective activity that follows a simulated clinical experience allowing the students and instructors to reflect upon and learn from the simulation [12].

Simulation offers an innovative teaching approach that attempts to mimic vital aspect of clinical cases [13]. When simulation incorporated with curriculum, it will become a powerful bridge between theory and practice by enhancing students' cognitive, associative, and independent skills [14]. A simulation-based learning strategy is a selection of planned activities that correspond to present or prospective situations in education and practice. It permits students to improve information skills and behaviors, evaluate and react to authentic scenarios in simulated settings by case studies [15]. Nursing students are rarely, if ever, requested to make critical and emergent decisions concerning real patients since to do so could expose patients to unnecessary risks. However, they will be required to make these types of decisions with little or no preparation as a graduate nurse [16]. This is one of the gaps that simulation is anticipated to fill. The objective of simulation in health care is to train and prepare students for clinical circumstances they may face [17]. Scenarios that replicate real life situations employ students in activities which teach, reinforce skills and build knowledge, and/or permit the utilization of preceding learned information. Through repetitive and purposeful actions, the student acquires competency and confidence in these abilities. Through experiential learning, the student gains the capability to develop clinical judgment. Reflection after the simulation exercise can aid the student in developing clinical reasoning and judgment [18]. Many studies have used patient care simulations to enrich learners' self-satisfaction with learning and self-confidence [5] [8] [19] [20] [21]. Additionally, It improves nursing clinical practice [22] [23], nursing knowledge and critical thinking [24] [25], communication skills [26], and clinical decision making [27]. Therefore, this paper is aimed to identify the best evidence on the effectiveness of using high fidelity simulation technology for learning outcomes in nursing education.

\section{Materials and Methods}

In this review, the search was performed by different international databases including Google Scholar, Scopus, Web of Science, Science Direct, Pub Med, Med- 
line, CINAHL, EBSCO, Cochrane, ERIC, Joanna Briggs Institute and EBSCO host using the keywords of "high fidelity simulation", "nurse", "student", "nursing education", and "outcome". Initially, in separated for meach new search added a new keyword until including all keywords. Later, these words were searched in combination with each other. However, the searching process was limited to following inclusion criteria: 1) written in English, 2) published between 2008 and 2018, 3) specifically related to high fidelity simulation used in the undergraduate nursing students, and 4) No restriction on article type. Studies including other health care professionals were excluded. The intervention is the use of high fidelity patient simulation technology in nursing education. The primary outcome is learning outcomes like satisfaction, confidence, clinical judgment, and decision making. The experimental designs, mixed method approach, quantitative and qualitative, and descriptive studies were considered and summaries to identify the best evidence.

However, review papers and incomplete reports in the form of editorials, opinion pieces, and conference abstracts have been excluded. Furthermore, a total of 1293 articles were retrieved and the initial evaluation for their titles abstracts took place. After evaluating and removing the duplicated articles, only 482 were found to be related to the topic of interest. Then, related articles were printed and read in full, following a secondary evaluation, 17 articles were exactly identified to cover the inclusion criteria. As a result, those Seventeen articles were included in this review (see Figure 1). Among the 17 articles, 1 articles were randomized control trial, 5 articles were mixed method approach, 8 were quasi-experimental, 1 article was qualitative, and 2 were correlational studies. The findings of each study were considered with codes for identification from the literature, summarization, synthesis and inferences, and discussion of findings for clarifying the interpretation themes.

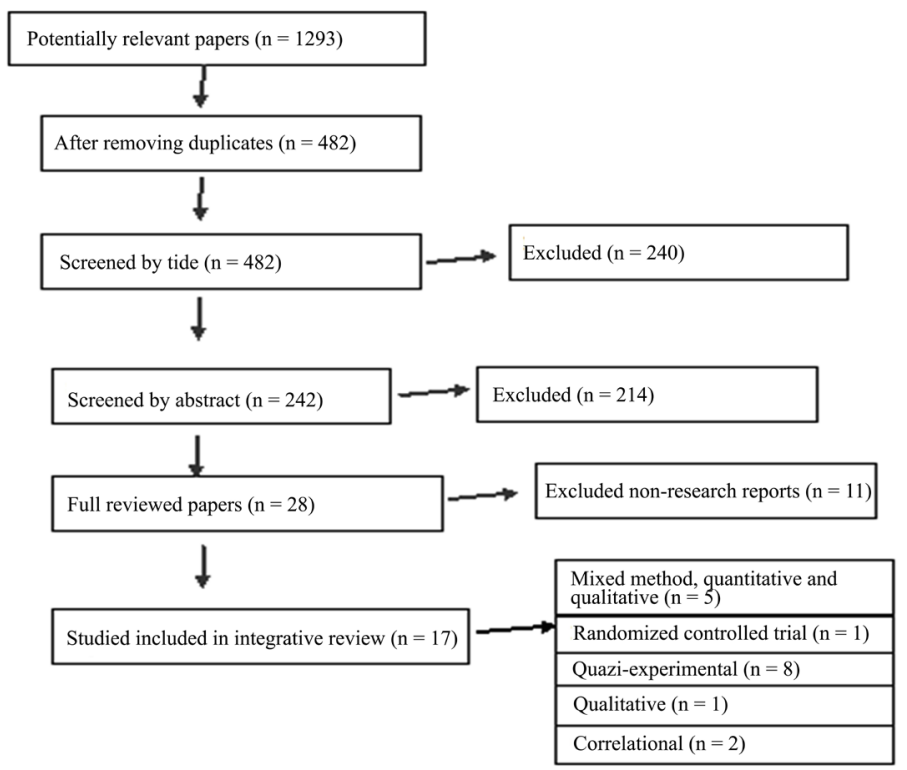

Figure 1. Search strategy and outcomes. 
Articles selected for retrieval were assessed for methodological validity by two independent reviewers prior to inclusion in the review. Critical appraisal assessment and review was done with agreement between the reviewers and a third reviewer was consulted when needed.

Data was extracted from the literature included in the review using standardized data extraction using specific details about the interventions, populations, study methods and outcomes of significance to the aim of the review. Then to display the data, all summarized pages were collected in a one matrix by using word sheet.

\section{Results}

Seventeen relevant articles have been reviewed. From each article the following data have been extracted: study purpose, design, sample, and findings (Table 1). Then, authors compared articles to identify themes. Review articles show that high-fidelity simulation improves clinical judgment and motivation among nursing students [28]. Students reported that they were better able to bridge theory to practice after the simulation experience [29]. It helped students to gain confidence by expecting the real clinical setting and giving them the opportunity to practice their assessments and problem-solving. Participants also identified learning the importance of prioritizing, of assessment skills and of recognizing abnormal findings, and knowing when and how to act [30]. The student's confidence in various clinical skills acquired after simulation clinical experience showed major increases in both self-efficacy and confidence than before the simulation clinical experience [30]. Clinical judgment skills of students weren't significant between who received structured debriefing following a high fidelity simulation experience [31].

The clinical simulation improves the student nurses' clinical judgment regarding the management of patients experiencing rapid clinical deterioration [32]. Engagement in simulation increases the nursing students of U.K. and U.S. for the aspects of noticing, interpreting, responding, and reflecting based on treatment [33]. The use of high-fidelity simulation is useful in skills performance and on clinical judgment more than low fidelity simulation. The increased clinical judgment may improve safety and nursing care among nursing students [34]. Nursing students $(\mathrm{N}=53)$ had significant self-confidence and clinical judgment in their first clinical semester [35]. Simulation helped the new nurses to solidify cognitive and psychomotor skills, sharpen their critical-thinking and leadership skills, and manage stress in critical situations [36]. Ten week orientation of new nursing graduates $(\mathrm{N}=26)$ hired to work in acute care areas of a large hospital had no significant in critical thinking and the Clinical Decision Making at the beginning and again at the conclusion of the intervention [37]. Second-year Nursing students $(\mathrm{N}=45)$ felt more competent and confident in their skill level [38]. Students $(\mathrm{N}=82)$ had increased knowledge of Advance Cardiac Life support (ACLS) and confidence in applying ACLS [39]. Nursing studentswho took 
Table 1. A summary of the characteristics of the included articles.

\begin{tabular}{|c|c|c|c|c|}
\hline Authors & Purpose & Sample Size & Design & Main Findings \\
\hline $\begin{array}{l}\text { Lasater and Nielsen } \\
\qquad(2009)\end{array}$ & $\begin{array}{l}\text { To evaluate the influence of } \\
\text { concept-based learning } \\
\text { activities on students' clinical } \\
\text { judgment development. }\end{array}$ & $\mathrm{n}=28$ & mixed methods & $\begin{array}{l}\text { Quantitative analysis revealed that students in the } \\
\text { treatment group scored significantly higher in all } \\
\text { phases of the clinical judgment rubric used in the } \\
\text { evaluation process. } \\
\text { The qualitative portion of this study found that } \\
\text { students reported that they were better able to } \\
\text { bridge theory to practice after the simulation } \\
\text { experiences. }\end{array}$ \\
\hline $\begin{array}{l}\text { Bambini, Washburn, } \\
\text { and Perkins (2009) }\end{array}$ & $\begin{array}{l}\text { To explore the effects of } \\
\text { simulated clinical experiences } \\
\text { on undergraduate nursing } \\
\text { students to investigate } \\
\text { self-efficacy and level of } \\
\text { confidence in clinical skills }\end{array}$ & $\mathrm{n}=112$ & mixed methods & $\begin{array}{l}\text { The quantitative study results showed that } \\
\text { student's confidence in various clinical skills } \\
\text { acquired after simulation clinical experience showed } \\
\text { major increases in both self-efficacy and confidence } \\
\text { than before the simulation clinical experience. The } \\
\text { analysis of the qualitative data showed that the } \\
\text { simulation experience made the participants gain } \\
\text { confidence by expecting the real clinical setting and } \\
\text { giving them the opportunity to practice their } \\
\text { assessments and problem-solving. }\end{array}$ \\
\hline
\end{tabular}

fidelity simulation on student self-confidence and clinical judgment using the LCJR

to compare clinical judgment

Mariani, Cantrell, Meakim, Prieto, and Dreifuerst (2013)

Johnson, Lasater, Hodson-Carlton, Siktberg, Sideras, \& Dillard., 2012

Lindsey and Jenkins (2013)

dan-Mansour (2016)

Konieczny, 2017 low-fidelity and high-fidelity simulation experience on the clinical judgment.

$\mathrm{n}=53$

a quasi-experimental study and clinical judgment in their first clinical semester

Debriefing was beneficial in sequencing of the learning experiences, especially in the

$\mathrm{n}=86 \quad$ mixed methods feedback/guided reflection improves critical thinking, persistence of reflective thinking for patient care

The findings indicated that there were significant differences with the control and treatment groups for the U.K. and U.S. for the aspects of noticing, interpreting, responding, and reflecting based on treatment and control groups

Findings from this study suggest that clinical $\mathrm{n}=79 \quad$ a quasi-experimental study knowledge and clinical judgment, specifically concerning rapid response systems

Results showed that the nursing students in the intervention group exhibited significant improvement in clinical judgment and motivation due to exposure to HFS than control group.

The outcome of the study revealed that the use of high-fidelity simulation is useful in teaching not only the skills of medication administration but also

$\mathrm{n}=126 \quad$ a quasi-experimenta the application of clinical judgment. The increased clinical judgment may improve safety and nursing care in medication administration among nursing students 


\section{Continued}

\begin{tabular}{|c|c|c|c|c|}
\hline Kaddoura (2010 & $\begin{array}{l}\text { To investigate the effects of } \\
\text { simulation on the clinical } \\
\text { decision making of new } \\
\text { graduate nurses during } \\
\text { hospital orientation }\end{array}$ & $\mathrm{n}=10$ & Qualitative & $\begin{array}{l}\text { Simulation helped the new nurses to solidify } \\
\text { cognitive and psychomotor skills, sharpen their } \\
\text { critical-thinking and leadership skills, and manage } \\
\text { stress in critical situations. }\end{array}$ \\
\hline Maneval et al. (2012) & $\begin{array}{l}\text { to measure clinical decision } \\
\text { making at the beginning and } \\
\text { again at the conclusion of the } \\
10 \text {-week orientation. }\end{array}$ & $\mathrm{n}=26$ & $\begin{array}{l}\text { a quasi-experimental } \\
\text { study }\end{array}$ & $\begin{array}{l}\text { Although scores for both groups improved from } \\
\text { pre-test to post-test, no significant differences were } \\
\text { found between the groups on either measure }\end{array}$ \\
\hline $\begin{array}{l}\text { Smith and Roehrs } \\
\qquad(2009)\end{array}$ & $\begin{array}{l}\text { To explore the effects of a } \\
\text { high-fidelity clinical } \\
\text { simulation experience with } \\
\text { junior level baccalaureate } \\
\text { nursing students enrolled in a } \\
\text { medical/surgical course }\end{array}$ & $\mathrm{n}=68$ & correlational study & $\begin{array}{l}\text { Nursing students were satisfied and self-confident } \\
\text { following their participation in the clinical } \\
\text { simulation experience. }\end{array}$ \\
\hline $\begin{array}{l}\text { Prescott and Garside } \\
\qquad(2009)\end{array}$ & $\begin{array}{l}\text { to evaluate simulation } \\
\text { strategies used to educate } \\
\text { second-year diploma nursing } \\
\text { students }\end{array}$ & $\mathrm{n}=73$ & $\begin{array}{l}\text { a mixed method } \\
\text { approach }\end{array}$ & $\begin{array}{l}\text { students noted that they felt more competent and } \\
\text { confident in their skill level }\end{array}$ \\
\hline $\begin{array}{l}\text { Tawalbeh \& Tubaishat } \\
\qquad(2013)\end{array}$ & $\begin{array}{l}\text { To examine the effect of } \\
\text { simulation on nursing } \\
\text { students' knowledge of } \\
\text { advanced cardiac life support } \\
\text { (ACLS), knowledge retention, } \\
\text { and confidence in applying } \\
\text { ACLS skills. }\end{array}$ & $\mathrm{n}=82$ & $\begin{array}{l}\text { randomized con- } \\
\text { trolled design study }\end{array}$ & $\begin{array}{l}\text { The experimental group showed higher knowledge } \\
\text { of ACLS and higher confidence in applying ACLS, } \\
\text { compared with the control group. }\end{array}$ \\
\hline Omer (2016) & $\begin{array}{l}\text { to explore the perception of } \\
\text { nursing students on their } \\
\text { satisfaction and } \\
\text { self-confidence after clinical } \\
\text { simulation experience }\end{array}$ & $\mathrm{n}=117$ & Correlational study & $\begin{array}{l}\text { Participants indicated that they have high level of } \\
\text { confidence in their abilities to conduct, appropriate } \\
\text { health assessments, perform effective intervention, } \\
\text { participate as an effective team member and } \\
\text { recognize patient deterioration events. }\end{array}$ \\
\hline $\begin{array}{l}\text { Lubbers \& Rossman } \\
\qquad(2016)\end{array}$ & $\begin{array}{l}\text { to determine the effects of a } \\
\text { Pediatric community } \\
\text { simulation experience on the } \\
\text { self-confidence of nursing } \\
\text { students in a private, liberal } \\
\text { arts college in the Midwestern } \\
\text { United States }\end{array}$ & $\mathrm{n}=44$ & $\begin{array}{l}\text { a quasi-experimental } \\
\text { study }\end{array}$ & $\begin{array}{l}\text { The results revealed that students who took the } \\
\text { Pediatric Community Based Simulation course re- } \\
\text { ported higher self-confidence after the course than } \\
\text { before the course. }\end{array}$ \\
\hline Sapyta \& Eiger (2017) & $\begin{array}{l}\text { to evaluate the impact of } \\
\text { simulation on nurses' } \\
\text { knowledge, confidence, and } \\
\text { accuracy of code } \\
\text { documentation }\end{array}$ & $\mathrm{n}=48$ & $\begin{array}{l}\text { quasi-experimental } \\
\text { design }\end{array}$ & $\begin{array}{l}\text { There was a statistically significant increase in } \\
\text { confidence following participation in the simulation } \\
\text { session }(p<0.001)\end{array}$ \\
\hline Saied (2017 & $\begin{array}{l}\text { to evaluate the effect of using a } \\
\text { simulation based scenarios on } \\
\text { the pediatricnursing students' } \\
\text { knowledge, self-efficacy, } \\
\text { satisfaction, and confidence }\end{array}$ & $\mathrm{n}=158$ & $\begin{array}{l}\text { quasi-experimental } \\
\text { design }\end{array}$ & $\begin{array}{l}\text { Students were satisfied with the simulation } \\
\text { experience and their self-confident scores were } \\
\text { higher after the simulation session. }\end{array}$ \\
\hline
\end{tabular}

the Pediatric Community Based Simulation course had higher self-confidence [40]. The simulation improved thenurses' knowledge, confidence, and accuracy of code documentation [41]. The simulation based scenarios had significant in- 
creased the pediatric nursing students' knowledge, self-efficacy, satisfaction, and confidence [42]. Juniorlevel baccalaureate nursing students $(N=68)$ enrolled in a medical/surgical course had improved satisfaction and self-confident following their participation in the clinical simulation experience [43]. King Saud bin Abdul Aziz University for Health Sciences nursing students $(\mathrm{N}=117)$ had improved their satisfaction and self-confidence in their abilities to conduct, appropriate health assessments, perform effective intervention, participate as an effective team member and recognize patient deterioration events after clinical simulation experience [44].

\section{Discussion}

In this integrative review, common themes emerged were self-satisfaction and confidence, clinical decision making and clinical judgment. Review studies revealed that baccalaureate nursing students, at various levels, ages and disciplines had higher satisfaction, self-confidence to face real clinical situations in a safe controlled environment. Simulation helped the new nurses to solidify cognitive and psychomotor skills, sharpen their critical-thinking and leadership skills, and manage stress in critical situations and learn to make sound decision-making [36] [37].

Higher satisfaction and self-confidence to recognize signs and symptoms of disease, obtaining the required knowledge from simulation to perform necessary tasks in clinical practice, developing the required skills from simulation to perform necessary task in clinical practice, and they can accurately assess an individual with any abnormalities [44]. At the same time, it involved physical assessment, medication administration, and the deterioration of patient condition requiring the students to call for additional professional assistance [43] and identified learning the importance of prioritizing, of assessment skills and of recognizing abnormal findings, and knowing when and how to act [30]. High -fidelity simulation received significantly higher scores in students' satisfaction and self-confidence [39] [42] and useful in teaching not only the skills of medication administration but also the application of clinical judgment [34].

Pre-briefing, simulation and debriefing was beneficial in sequencing of the learning experiences, especially in the feedback/guided reflection improves critical thinking, persistence of reflective thinking for patient care [31] particularly when enhanced with role modelling, is an effective method for enhancing and strengthening the student's development of clinical judgment [33].

It improves knowledge, skill, clinical judgment, communication, and accuracy of documentation [28] [32] [35] [38] [40] [41] and transfers of theory into nursing practice [29] with no-risks in the safe environment [34]. Therefore, simulation provides visualization of unexpected emergencies in a safe environment to develop assessment and management practice. Hence, HPS supports students' self-satisfaction, confidence, clinical judgment, and knowledge and skill performance with debriefing. HPS provides real clinical experiences for teaching 
concepts and application of nursing using patient scenarios of varying acuity.

\section{Conclusions}

The recognition of the possible value of simulation in nursing education has been grown. Overall, the literature supports the need to include simulation as a teaching strategy in nursing curriculum. Utilization of HFS for enhancing learning outcome in nursing education is a positive and innovative method. We especially highlight the importance of the high fidelity simulation in eliminating the passive role of students during the learning process. The learning process became more student centred rather than content centred. Satisfaction and confidence with safe controlled environments are influenced by knowledge, skill performance, and critical thinking abilities. The use of high-fidelity simulation into the undergraduate nursing education can improve the quality of learning, can help students for leadership, clinical judgment, manage care and promote decision-making. This can bridge the gap between theory and clinical practice among nurses for application and translation to bedside practice. Pre briefing and debriefing provide responding sessions to reflect knowledge and exchange vital elements in nursing care.

Integration of HFS in nursing education can reinforce the standards of nursing practice and student intended learning outcomes for safe nursing practice. In addition, simulation could directly benefit nursing student interactions with their learning in environment, self-directed, and supporting the idea of independent meaningful learning.

\section{References}

[1] Potgieter, E. (2012) Clinical Teaching: Developing Critical Thinking in Student nurses. Professional Nurse Today, 16, 4e8.

[2] Pongmarutai, T. (2010) Application of a Judgment Model toward Measurement of Clinical Judgment in Senior Nursing Students. Dissertation. http://digitalscholarship.unlv.edu/thesesdissertations

[3] Rowles, C.J. and Russo, B.L. (2009). Strategies to Promote Critical Thinking and Active Learning. In Billings, D.M. and Halstead, J.A., Eds., Teaching in Nursing, Saunders, St. Louis, 238-262.

[4] Purling, A. and King, L. (2012) A Literature Review: Graduate Nurses' Preparedness for Recognising and Responding to the Deteriorating Patient. Journal of Clinical Nursing, 21, 23-24. https://doi.org/10.1111/j.1365-2702.2012.04348.x

[5] Dearmon, V., Graves, R.J., Hayden, S., Mulekar, M.S., Lawrence, S.M. and Farmer, J.E. (2013) Effectiveness of Simulation-Based Orientation of Baccalaureate Nursing Students Preparing for Their First Clinical Experience. Journal of Nursing Education, 52, 29-38. https://doi.org/10.3928/01484834-20121212-02

[6] Reilly, A. and Spratt, C. (2007) The Perceptions of Undergraduate Student Nurses of High-Fidelity Simulation-Based Learning: A Case Report from the University of Tasmania. Nurse Education Today, 27, 542-550.

https://doi.org/10.1016/j.nedt.2006.08.015

[7] Rushton, M. (2015) Simulation and the Student Pathway to Critical Care. British 
Journal of Cardiac Nursing, 10, 95-98. https://doi.org/10.12968/bjca.2015.10.2.93

[8] Crocetti, J. (2014) Nursing Clinical Faculty Self-Efficacy Following an Orientation Using Simulation. Nursing Education Perspectives, 35, 193-194.

https://doi.org/10.5480/12-819.1

[9] Hayden, J., Smiley, R., Alexander, M., Kardong-Edgren, S. and Jeffries, P. (2014) Supplement: The NCSBN National Simulation Study: A Longitudinal, Randomized, Controlled Study Replacing Clinical Hours with Simulation in Prelicensure Nursing Education. Journal of Nursing Regulation, 5, C1-S64.

[10] Hsu, L., Chang, W. and Hsieh, S. (2015) The Effects of Scenario-Based Simulation Course Training on Nurses' Communication Competence and Self-Efficacy: A Randomized Controlled Trial. Journal of Professional Nursing, 31, 37-49. https://doi.org/10.1016/j.profnurs.2014.05.007

[11] Veltri, L.M., Rowe, J.M., Bell, K.J., Arwood, E.L. and Kindler, L.L. (2014) The Maternal-Newborn Assessment Study: Can Simulation Replicate the Clinical Learning Experience in Undergraduate Nursing Education? Journal of Obstetric, Gynecologic \& Neonatal Nursing, 43, S81-S85.

[12] Dreifuerst, K.T. and Decker, S.I. (2012) Debriefing: An Essential Component for Learning in Simulation Pedagogy. In: Jeffries, P., Ed., Simulation in Nursing Education, National League for Nursing, New York, 2nd Edition, 105-129.

[13] Buckley, T. and Gordon, Ch. (2011) The Effectiveness of High-Fidelity Simulation on Medical-Surgical Registered Nurses' Ability to Recognize and Respond to Clinical Emergencies. Nurse Education Today, 31, 716-721.

https://doi.org/10.1016/j.nedt.2010.04.004

[14] Wotton, K., Davis, J., Button, D. and Kelton, M. (2010) Third-Year Undergraduate Nursing Students' Perceptions of High-Fidelity Simulation. Journal of Nursing Education, 49, 632-639. https://doi.org/10.3928/01484834-20100831-01

[15] Meakim, C., Boese, T., Decker, S., Franklin, A.E., Gloe, D., Lioce, L. and Borum, J.C. (2013) Standards of Best Practice: Standard I: Terminology. Clinical Simulation in Nursing, 9, 3-11. https://doi.org/10.1016/j.ecns.2013.04.001

[16] Burns, P. and Poster, E.C. (2008) Competency Development in New Registered Nurse Graduates: Closing the Gap between Education and Practice. The Journal of Continuing Education in Nursing, 39, 67-73. https://doi.org/10.3928/00220124-20080201-03

[17] Harder, B.N. (2010) Use of Simulation in Teaching and Learning in Health Sciences: A Systematic Review. Journal of Nursing Education, 49, 23-28. https://doi.org/10.3928/01484834-20090828-08

[18] Dreifuerst, K.T. (2009) The Essentials of Debriefing in Simulation Learning: A Concept Analysis. Nursing Education Perspectives, 30, 109-114.

[19] Dunn, K.E., Osborne, C. and Link, H.J. (2014) High-Fidelity Simulation and Nursing Student Self-Efficacy: Does Training Help the Little Engines Know They Can? Nursing Education Perspectives, 35, 403-404. https://doi.org/10.5480/12-1041.1

[20] Schlairet, M. (2011) Simulation in an Undergraduate Nursing Curriculum: Implementation and Impact Evaluation. The Journal of Nursing Education, 50, 561-568. https://doi.org/10.3928/01484834-20110630-04

[21] Jeffries, P.R. and Rizzolo, M.A. (2006) Designing and Implementing Models for the Innovative Use of Simulation to Teach Nursing Care of Ill Adults and Children: A National Multisite, Multi-Method Study. National League for Nursing, New York.

[22] Kinsman, L., Buykx, P., Cant, R., Endacott, R. and Missen, K. (2012) The FIRST 2ACT Simulation Program Improves Nursing Practice in a Rural Australian Hos- 
pital. Australian Journal of Rural Health, 20, 270-274.

[23] McCaughey, C.S. and Traynor, M.K. (2010) The Role of Simulation in Nursing Education. Nurse Education Today, 30, 827-832.

[24] Schubert, C. (2012) Effects of Simulation on Nursing Knowledge and Critical Thinking in Failure to Rescue Events. The Journal of Continuing Education in Nursing, 43, 3475-3484.

[25] Secomb, J., McKenna, L. and Smith, C. (2012) The Effectiveness of Simulation Activities on the Cognitive Abilities of Undergraduate Third-Year Nursing Students: A Randomized Control Trial. Journal of Clinical Nursing, 21, 3475-3484.

[26] Young, K., Eun, K. and Sook, L. (2012) Effects of Simulation-Based Education on Communication Skill and Clinical Competence in Maternity Nursing Practicum. Korean Society of Women Health Nursing, 18, 312-320.

[27] Powell-Laney, S., Keen, C. and Hall, K. (2012) The Use of Human Patient Simulators to Enhance the Clinical Decision Making of Nursing Students. Education for Health (Abingdon), 25, 11-15.

[28] Fawaz, M.A. and Hamdan-Mansour, A.M. (2016) Impact of High-Fidelity Simulation on the Development of Clinical Judgment and Motivation among Lebanese Nursing Students. Nurse Education Today, 46, 36-42.

https://doi.org/10.1016/j.nedt.2016.08.026

[29] Lasater, K. and Nielsen, A. (2009) Reflective Journaling for Clinical Judgment Development and Evaluation. Journal of Nursing Education, 48, 40-44. https://doi.org/10.3928/01484834-20090101-06

[30] Bambini, D., Washburn, J. and Perkins, R. (2009) Outcomes of Clinical Simulation for Novice Nursing Students: Communication, Confidence, Clinical Judgment. Nursing Education Perspectives, 30, 79-82.

[31] Mariani, B., Cantrell, M.A., Meakim, C., Prieto, P. and Dreifuerst, K.T. (2013) Structured Debriefing and Students' Clinical Judgment Abilities in Simulation. Clinical Simulation in Nursing, 9, e147-e155. https://doi.org/10.1016/j.ecns.2011.11.009

[32] Lindsey, P.L. and Jenkins, S. (2013) Nursing Students' Clinical Judgment Regarding Rapid Response: The Influence of Clinical Simulation Education Intervention. Nursing Forum, 48, 61-70. https://doi.org/10.1111/nuf.12002

[33] Johnson, E.A., Lasater, K., Hodson-Carlton, K., Siktberg, L., Sideras, S. and Dillard, N. (2012) Geriatrics in Simulation: Role Modeling and Clinical Judgment Effect. Nurse Education Perspectives, 33, 176-180. https://doi.org/10.5480/1536-5026-33.3.176

[34] Konieczny, L. (2017) Clinical Judgment in Medication Administration among Nursing Students. Clinical Nursing Studies, 5, 52-58. https://doi.org/10.5430/cns.v5n4p52

[35] Blum, C.A., Borgland, S. and Parcells, D. (2010) High-Fidelity Nursing Simulation: Impact on Student Self-Confidence and Clinical Competence. International Journal of Nursing Education Scholarship, 7, 1-14. https://doi.org/10.2202/1548-923X.2035

[36] Kaddoura, M.A. (2010) New Graduate Nurses' Perceptions of the Effects of Clinical Simulation on Their Critical Thinking, Learning, and Confidence. The Journal of Continuing Education in Nursing, 41, 506-516. https://doi.org/10.3928/00220124-20100701-02

[37] Maneval, R., Fowler, K.A., Kays, J.A., Boyd, T.M., Shuey, J., Harne Britner, S. and Mastrine, C. (2012) The Effect of High-Fidelity Patient Simulation on the Critical 
Thinking and Clinical Decision-Making Skills of New Graduate Nurses. Journal of Continuing Education in Nursing, 43, 125-134. https://doi.org/10.3928/00220124-20111101-02

[38] Prescott, S. and Garside, J. (2009) An Evaluation of Simulated Clinical Practice for Adult Branch Students. Nursing Standard, 23, 35-40.

https://doi.org/10.7748/ns2009.02.23.22.35.c6776

[39] Tawalbeh, L. and Tubaishat, A. (2014) Effect of Simulation on Knowledge of Advanced Cardiac Life Support, Knowledge Retention, and Confidence of Nursing Students in Jordan. Journal of Nursing Education, 53, 38-44.

[40] Lubbers, J. and Rossman, C. (2016) The Effects of Pediatric Community Simulation Experience on the Self-Confidence and Satisfaction of Baccalaureate Nursing Students: A Quasi-Experimental Study. Nurse Education Today, 39, 93-98. https://doi.org/10.1016/j.nedt.2016.01.013

[41] Sapyta, Y. and Eiger, C. (2017) Improving Pediatric Nurses' Knowledge, Accuracy, and Confidence through Code Documentation Simulation. Clinical Simulation in Nursing, 13, 278-283. https://doi.org/10.1016/j.ecns.2017.02.003

[42] Saied, H. (2017) The Impact of Simulation on Pediatric Nursing Students' Knowledge, Self-Efficacy, Satisfaction, and Confidence. Journal of Education and Practice, 8, 95-102.

[43] Smith, S.J. (2008) High-Fidelity Simulation in Nursing Education: Design Characteristics and Their Effect on Student Satisfaction and Self-Efficacy. Doctoral Dissertation.

[44] Omer, T. (2016) Nursing Students' Perceptions of Satisfaction and Self-Confidence with Clinical Simulation Experience. Journal of Education and Practice, 7, 131-138. 